\title{
Older adult's recovery from hip fracture: A literature review
}

David J. Healee RGN, MA (Doctoral Candidate, Nursing Lecturer), Antoinette McCallin PhD (Director, National Centre for Interprofessional Education and Collaborative Practice), Marion Jones PhD (Associate Professor and Associate Dean, Postgraduate)

AUT University, Private Bag 92006, Auckland, New Zealand

\begin{abstract}
This paper examines studies on older adult's recovering from hip fracture and views these in relation to practice. A metasearch engine was used to access health databases to identify studies relevant to recovery from hip fracture that occurs predominantly in the older adult. Three themes emerged: professional; quality of life, and ageing status. Results suggest recovery has a predominant functional restorative focus although recovery outcome is also influenced by physical function and psychosocial factors. Results suggest that the patient-centric approach has been lost in the drive for organisational efficiency has potentially driven care delivery, which has emphasised safer interventions and improved programmes. This has reduced complications and shortened length of stay in hospital but the psychosocial factors that have a long-term affect on recovery have been lost altogether. Investigating the patient-centric approach to care for older adults recovering from hip fracture is required to balance the organisational efficiency within healthcare systems. Mental health recovery models may provide such a framework to review the patient focused approach.
\end{abstract}




\section{Introduction}

One prime objective for clinicians is to have older adults recover from hip fracture and regain functional independence. Research knowledge about recovery has increased in recent years. Recovery knowledge includes research about physical conditions and mental health illness (Richmond et al., 2000; Williams et al., 2007; Zalon, 2004). Recovery from a physical condition describes physical restoration and functional return following a specific disease, injury or healthcare intervention.

In this paper literature about the older adult's recovery from hip fracture is reviewed. Surprisingly, while recovery is affected by physical, psychological and social influences, it is usually defined professionally (Jacobson and Greenley, 2001; Repper and Perkins, 2003; Roberts and Wolfson, 2006). Recovery in health is often determined by achieving predetermined criteria relative to a specific physical condition. For example, hip fracture recovery may be determined by an ability to mobilise post-fracture, as this function is indicative of achieving a previous state and denotes restoration of function.

The focus of restorative recovery based on disease or injury, highlights interventional treatments and is supported by evidenced-based medicine (Roberts and Wolfson, 2006). For example, cardiac, neurological, abdominal or orthopaedic conditions are assessed against fatigue, depression, or physiological changes that impact recovery (Barnason et al., 2008; Dowswell et al., 2000; Ely et al., 2002; Givens et al., 2008). The 'physical approach' to recovery emphasises the trajectory a condition should follow, allowing recovery to be measured against specific milestones of achievement (Dorsett,1991; Halcomb and Davidson, 2005). Variables within the trajectory to be examined, explained and improvements made to treatment regimes recommended (Dorsett, 1991; Godfrey and Townsend, 2008; Halcomb and Davidson, 2005; Horan and Clague,1999; Kearney, 1999).

Improving recovery for older adults is important, as the hip fracture rates increase in an ageing population (Chang et al., 2004; Ishizaki et al., 2004; Johnell and Kanis, 2004; Khasraghi et al., 2003; Stephenson et al., 2003). Improved anaesthetics, surgical techniques, and post-operative management, and functional rehabilitation programmes have enhanced recovery outcomes. Research is critical to support the principles of the Bone and Joint Decade (2000-2010). This paper reviews current research and gives direction for the future. 


\section{Method}

Selected literature was examined to gain some insight into how recovery from hip fracture in older adults was perceived by healthcare professionals. Using a metasearching strategy, the term recovery was entered as a search parameter. Modifications included: older adult, elderly, illness/injury, hip fracture and fractured neck of femur. English titles and abstracts were reviewed. If the abstract met the search criteria, full text versions were reviewed.

Approximately 90 articles were reviewed. Three themes emerged: professional focus, quality of life, and ageing status. Fig. 1 outlines the major themes from the literature reviewed.

The professional theme centred on interventional and predictive functionality associated with hip fracture recovery. A quality of life theme was related to change following hip fracture and included measurement, gender/culture and experience. An ageing status theme highlighted the age and co-morbidities factors related to older adults. Fig. 1 will be used as a structural guideline for discussing the literature.

Figure 1: Themes on recovery from hip fracture

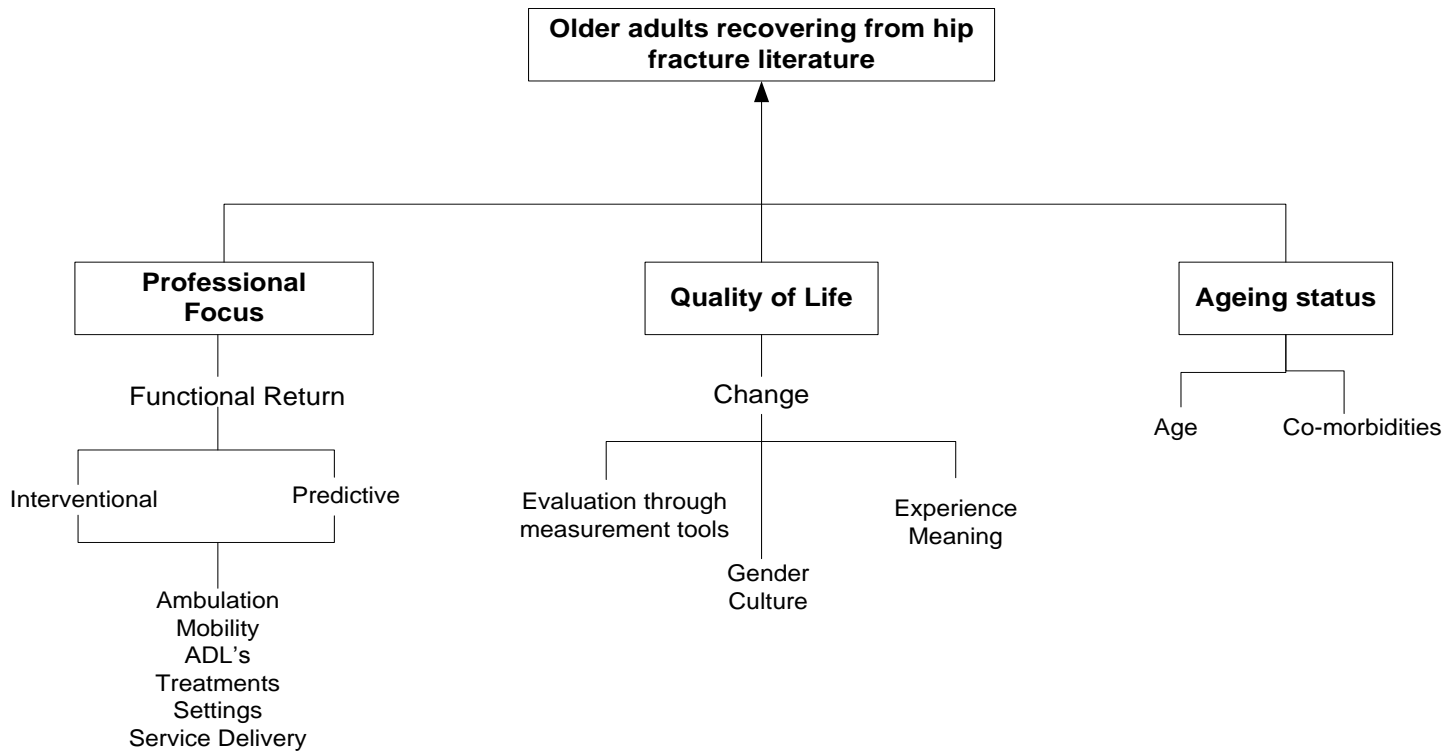




\section{Results}

\section{Professional focus}

There is a strong professional emphasis on understanding how functional recovery is regained post-fracture. Professional understanding of functional restoration suggests that the aim of recovery is to restore the older adult to their fullest physical, mental and social capabilities (Maher et al., 2002; NZGG, 2003). Functional recovery outcomes were generally measured according to mobility, activities of daily living, dependence levels, transferring ability and self-care. Functionality research was grouped as follows. The first group examined definition and measurement of function and outcomes, reviewing achievable restoration levels. The second group explored healthcare interventions, professional and environmental factors that enhanced recovery. The third group focused on recovery prediction. Often the themes were intertwined.

According to Magaziner et al. (2000) defining functionality according to specific function is useful to determine recovery potential. Regaining physical function occurs in a sequential process, which assists clinicians to evaluate recovery and disability prospects of older adults. The functional areas included: upper and lower extremities, physical and instrumental activities of daily living, gait and balance, social, cognitive, and affective function (Magaziner et al., 2000). In contrast, Zuckerman et al. (2000) measured recovery function and compared it to prefracture independence functioning. Their tool assessed basic and instrumental activities of daily living and mobility as potential indicators of functional restoration following hip fracture (Zuckerman et al., 2000a,b). Eastwood et al. (2002) presented an alternative approach measuring functional outcomes in terms of locomotion, transfers, sphincter control and self-care.

Professionals have used functional return measures to help clinicians assess levels of function and use resources appropriately (Eastwood et al., 2002; Egol et al., 1997; Giaquinto et al., 2000; Guccione et al., 1996; Koot et al., 2000). Magaziner et al. (2003) compared hip fractured patients with community dwelling older adults where activities of daily living, walking, transferring and grooming were examined.

Allowing for pre-existing conditions, age and functional limitations it was apparent that a permanent decline in function postfracture is common. Lin and Chang (2004) 
also reported functional decline concluding that most patients did not return to prefracture status and significant recovery was completed at 3 months. Recovery was dependent on outdoor pre-walking ability prior to the fracture (Lin and Chang, 2004).

Interestingly, professional interventions such as surgery and treatments, nursing factors, physical therapy, co-ordination of care may improve functional recovery posthip fracture. The type of prosthesis such as total hip joint replacement for instance, improves recovery (Mouzopoulos et al., 2008). Surgical intervention and functional recovery relationships have been evaluated to determine effectiveness of prostheses, techniques, and treatment decision-making (Lichtblau, 2002; NZGG, 2003; Siu et al., 2006; Tanaka et al., 2003). Koot et al. (2000) took a different approach examining functional and mobility recovery outcomes and reported that age, co-existing disease, general and local complications were significant. Clearly, appropriate treatment minimises potential risks from complications.

Nursing factors that impact on hip fracture recovery focused on specific interventions that potentially enhance recovery prospects (Barangan, 1990). Nursing is well positioned to prevent or reduce complications post-fracture through improved assessment and interventions. Nurses though needed to understand the multiple factors such as age, gender, type of fracture repair, general medical condition, confusional state, depression and iatrogenic complications that also affect recovery (Barangan, 1990). Jagmin (1998) examined post-operative mental status, concluding that nurses should be aware that confusion is common in some older post-operative patients irrespective of their prior condition. Confusion compromises recovery (Jagmin, 1998). As patients often fell owing to post-operative confusion, Lappe (1998) suggested that nurses need a hip fracture awareness update to improve prevention practices. Titler et al. (2006) noted that the younger patient, admitted from home with a spouse to return to, had an improved chance of returning home, and which relevant nursing interventions impacted on discharge.

Professionally, targeted physical therapy improves recovery prospects for older adults post hip fracture. Tsauo et al. (2005) compared in-home physical therapy with standard in-hospital treatment. If physical therapy continued after discharge, full function was regained earlier with added quality of life benefits. However, this affected clinical practice and resources (Tsauo et al., 2005). Oldmeadow et al. (2006) compared the effects of early mobilisation against delayed ambulation post- 
operatively. Early ambulation promoted functional recovery with an increased discharge rate to the home environment and reduced the need for higher level of care. Extra physiotherapy reduced functional impairments post-surgery (Oldmeadow et al., 2006).

Choong et al. (2000) compared standard treatment regimes with clinical pathway management. Clinical pathways decreased length of stay without increasing complication rates. Similar studies examined the implementation of the clinical pathway progression in service delivery (Fisher et al., 2006; Koval et al., 2004; Koval and Cooley, 2005; Morris and Zuckerman, 2002; Olsson et al., 2006; Roberts et al., 2004; Watters \& Moran, 2006).

These studies suggest that 'fast-tracking' older adults through the hip fracture process minimises potential complications, reduces length of stay and improves the likelihood of discharge to a suitable residence. Factors such as time from admission to surgical intervention, mobilisation and discharge are improved through reduced variance. However, the older adult experience of the process is not well explored in clinical pathways studies.

Another theme in the literature is that rehabilitation units improve recovery outcome. However, Jette et al. (1987) found there was no benefit to the outcomes of recovery when enhanced rehabilitation regimes were provided. The impact on mortality, discharge status, and level of recovery was not statistically significant to warrant increased rehabilitation programmes. Ganz et al. (2007) and Giaquinto et al. (2000) argue that the rehabilitation environment focuses on functionality, thus ensures appropriate interventions and resources are directed to support an individual's recovery. Overall, older adults rehabilitated in specific facilities generally improve so that type of environment seems beneficial too and suggests clinical best practice.

When professionals collaborate recovery outcomes improve (Lichtblau, 2002; Morris and Zuckerman, 2002). Professional collaboration affects the quality of care (Fisher et al., 2006; Koval and Zuckerman, 1994; Lichtblau, 2002; Morris and Zuckerman, 2002; NZGG, 2003; Siu et al., 2006; Watters and Moran, 2006). The complex nature of recovery suggests that healthcare staff focus on operative interventions, a collaborative approach to care, good psychosocial evaluation and social support to ensure recovery outcomes are maximised (Koval and Zuckerman, 1994). 
The professional view of recovery suggests that predicting functional recovery is maximised if psychosocial, dependency, potential for mobilisation and activity factors are considered in recovery prediction. Social support networks may influence recovery as do physical symptoms post-fracture and surgery. Cummings et al. (1988) suggested that the greater the number of social supports prior to the hip injury the more likely complete recovery was possible. In addition, Mossey et al. (1989) argued that psychosocial factors affect recovery. Social connectedness, personality and self-rated health all impacted recovery prospects. While there may be a decline in physical function, psychosocial factors remained stable during recovery. However, Mossey et al. noted that depression post-surgery inhibited recovery and needed to be treated early by clinicians. Givens et al. (2008) recommended that the prevalence of depressive symptoms, cognitive impairment and delirium on functional recovery were measured using standard validated tools. Recovery declines with an increased decline in function associated with mood or cognitive disorders such as depression and confusion (Givens et al., 2008). As functional recovery peaks at approximately 6 months, social supports and psychosocial factors underpinning recovery become increasingly important (Magaziner et al., 1990).

If professionals can predict activity and mobilisation potential post-fracture, clinicians can plan therapy interventions to improve functional outcome and minimise complications. Magaziner et al. (1990) evaluated predictors for walking and activities of daily living noting optimal post-fracture mobilisation was reached at 6 months. Similar studies (Cree, 2004; Khasraghi et al., 2003; NZGG, 2003; Tanaka et al., 2003; Titler et al., 2006; Young et al., 1997) concluded that functional activity generally stabilised at approximately four to 6 months though multiple factors impacted on achieving a final functional outcome. Such factors included age of patient, type of fracture, underlying bone or physical condition, gender, race and socioeconomic factors. According to Ingemarsson et al. (2003) walking ability and activity at 1 year indicated factors such as physical aspects, pain and bone density, impacted on improved function and indicated walking and balance prospects for 1 year post-fracture. Knowledge about a patients prior walking habits and degree of independence supported the prediction (Ingemarsson et al., 2003). Assisting clinicians to minimise risk and maximise outcome potential through 
prediction supports quality of care delivery as well as influencing quality of life for the older adult.

\section{Quality of life}

Impact on an older adult's perceived life situation is evident if viewed through a 'quality of life' lens. This suggests that recovery from hip fracture is affected by more than physical change. Quality of life is "health status" (van Balen et al., 2003, p. 507) that is measured in three dimensions. That is, functionally, psychologically and social health, determine a health related quality of life. Health related quality of life can be measured with assessment of functional changes and examined for psychosocial changes by exploring gender, culture, experience or meaning, all of which impact social health. This approach provides a broader measurement of recovery.

Changes in health related quality of life post-hip fracture may be related to actual or perceived functional differences which can be measured. The most common measure of quality of life is the Short Form-36 which has been used in hip fracture research from 2000. Functional measurement tools included: Barthel Index, Timed Up \& Go, Berg Balance scale, Rehabilitation Activities scale, Nottingham Health Profile, COOP/WONCA, and the Cummings Hip scale. Hall et al. (2000), Peterson et al. (2002), and van Balen et al. (2003) combined such measurement tools with the SF-36 examining impacts of functional loss on quality of life. Patient reported outcome measures (PROMs) feature prominently in the UK. Two types of PROMs are presented. Firstly, are the standardised questionnaires the measure patient assessed information pre and post an elective procedure (Dawson et al., 2010). Secondly, is the combination of different types of evaluation tools to assess different perspectives on the outcomes of quality of life (Garratt et al., 2002; Greenhalgh et al., 2005; Ostendorf et al., 2004). For example, the combining of the SF-36, a disease specific evaluation tool and patient reported outcomes creates a wider perspective for determining overall outcome. These processes have identified specific interventions that could be relevant to older adult's recovery.

Validated assessment tools measuring non-physical aspects against functional factors may offer clinicians a quantifiable outcome about quality of life issues. The SF-36, reports a definitive decrease in physical function, role participation and social activities following hip fracture compared to control groups (Boonen et al., 2004; 
Hallberg et al., 2004; Randell et al., 2000; Shyu et al., 2004; Van Balen et al., 2001). This was evident irrespective of the time difference in the studies, from 3 months to 2 years. Clearly, perceived quality of life differences continue even though functional restoration had occurred. Apparently, non-physical factors impact recovery more than functional factors.

Gender and culture may impact on quality of life. Females have been thoroughly examined (Lofman et al., 2002; Norton et al., 1995; Sanders et al., 1999a, b). Interestingly, Pande et al. (2006) and Hawkes et al. (2006) examined the difference in recovery between males and females, noting that there is a higher mortality and morbidity potential for males following hip fracture although this was influenced by prefracture status. Cultural differences were evident in New Zealand in that Norton et al. (1995) noted that within Maori and Pacific Island groups hip fracture rates were lower compared to the Caucasian population. This was comparable to international incidence rates where the hip fracture occurred predominantly among white females. However, there were no studies noting differences between the cultural groups in New Zealand related to quality of life post-fracture. Kirk-Sanchez (2004) suggested distinctive cultural and psychological factors were relevant to quality of life in Cuban Americans. Premorbid limitations affecting quality of life post-fracture related to mental health illness, being male, in an older age group, or having a condition such as heart disease or diabetes (Kirk-Sanchez, 2004). Similar culture specific studies from Asian countries noted how hip fracture in an ageing population affected quality of life (Shyu et al., 2004; Tanaka et al., 2003; Tsauo et al., 2005). This 'cultural filter' adds a different dimension to the meaning of recovery. Mossey et al. (1989) observes that post-surgical depression, personality type, social connectedness and self-rated health status are significant for recovery. It was clear that the 'invisible' psychosocial factors were less visible in recovery. Determining which psychosocial factors influenced recovery is important for clinicians planning interventions.

Quality of life has been examined in relation to the experience of having a hip fracture (Archibald, 2003; Borkan et al., 1991; Hunt and Stein, 2004; Robinson, 1999; Ziden et al., 2008). According to Borkan et al. (1991) the meaning of the experience was threefold. First, was how the person explained the fracture, second, the sense of disability perceived, and third, futurity - how the individual perceived their future. Innovative for its time, Borkan, Quirk, and Sullivan's study suggested meaning could 
be applied to functional status as perceived by the older adult that not only impacted on recovery outcomes but also improved clinician understanding of the patient experience. In contrast, Robinson (1999) examined how behaviours promoted or inhibited recovery transition. Apparently prefracture adaptive behaviours were significant for recovery and good adaption techniques generally promoted recovery. Not surprisingly, poor adaptive behaviours inhibited recovery. If healthcare teams are aware of these issues care planning and delivery could be enhanced.

Improving knowledge for clinicians impacts upon quality of life. Archibald's (2003) noted that there were four distinct phases in recovery - injury, pain, recovery, and disability. Understanding of these would improve nursing intervention planning, and minimise physical and psychological complications thus improving quality of life for the older adult. The hip fracture experience was examined by Ziden et al. (2008) with people being interviewed soon after discharge from hospital. Findings suggest that multidimensional change impacts physically, socially and psychologically and this emphasises uncertainty about the future. Clinicians understanding of such changes to body function, self-perception and overall impact, may improve planning and delivery of care (Ziden et al., 2008).

Quality of life perceptions of hip fracture and recovery differ if injury is hypothetical. Hunt and Stein (2004) explored how 'well-elders' viewed potential injury. Expectations of recovery were generally optimistic as predictions were compared with their current life situation. Clearly, good attitudes prior to hip fracture potentially enhance recovery prospects (Hunt and Stein, 2004). With an ageing population and potential for increased hip fracture incident rates, knowledge about the multiple factors that influence recovery is important.

\section{Ageing status}

The third theme - ageing status - recognises that the age and health state of an older adult influences hip fracture recovery. There is an ageing population worldwide and an increase in older adults presenting with hip fracture (ACC, 2005; Chang et al., 2004; Gullberg et al., 1997; Ministry of Health, 2003). Older age is generally defined as 65 years and above (ACC, 2005; Ministry of Health, 2003, 2007; NZGG, 2003). According to Norton et al. (1995) and Kannus et al. (1996) the potential for hip fracture increases with advancing age especially in the over 85 year age group. However, the mean age of studies examining hip fracture tended towards the mid- 
seventies to mid-eighties age range. Conversely, a number of studies examined an older age group - 90 years and over. Many of the studies noted that pre-existing conditions affect recovery.

Being older at time of fracture means that recovery outcomes decline. Adults in their seventies and eighties had a poorer outcome following hip fracture (Kannus et al., 1996; Melton III, 1996; Young et al., 1997). A mean age of 83 years was noted as significant (van Balen et al., 2001) who also reported that seventy percent (70\%) of participants with hip fracture had a co-existing condition. Titler et al. (2006) observed that age affected recovery and discharge destination, while Young et al. (1997) report an increased complexity in the older adult recovering from hip fracture.

However, age alone does not automatically reduce outcomes although it certainly influences treatment decisions. While rehabilitation programmes improved recovery, complications and co-morbidities are more common. For example, Shah et al. (2001) compared those who were 90 years plus with a younger age group, noting an increased risk of death, decreased functional return and longer length of hospital stay as significant issues in the older age group. Increased risks generally impacted negatively on basic activities for this age group. Tanaka et al. (2003) reported increased risks of non-ambulation and death in this age group but suggested specific surgical interventions may benefit this older age group. Anticipating complications following surgery on the very old can determine where relevant resources and interventions would be best utilised (Cree, 2004; Tanaka et al., 2003). Giaquinto et al. (2000) argue that very old people can have a favourable outcome after hip fracture.

Age impacts on recovery from any fracture but it is noticeably significant when there are coexisting conditions. For example, the Older People's Health Chart Book (2006) indicated that hospitalisation of older people from 75 years and above was most often from falls with unintentional injury (ACC, 2005; Ministry of Health, 2007). Falls are often a precursor to hip fracture (Chang et al., 2004; Kannus et al., 1996; Lappe, 1998; Norton et al., 1995; Sanders et al., 1999a). Many older adults have preexisting conditions such as osteoporosis, although these people live successfully in the community if they are well managed (Chang et al., 2004; Ishizaki et al., 2004; Koval et al., 1996). However, co-existing conditions may require increased resources and an increase hospital stay. Examination of comorbidities and their effect on recovery from hip fracture agree that the complex interplay of hip fracture treatments and co-existing 
conditions must be managed carefully, if the impact on recovery outcomes and the economic impacts on the health sector are to be minimised (Egol et al., 1997; Ishizaki et al., 2004; Khasraghi et al., 2003; Koot et al., 2000; Young et al., 1997).

\section{Discussion}

It was noticeable that the main emphasis in the literature was on functional restoration post-hip fracture. However, there was acknowledgement of ageing populations, increased healthcare service demand and improved physical and psychosocial understanding of hip fracture recovery. Several themes stood out: restoration of function; the need to improve co-ordinated care; and the need for the patient perspective of recovery. These are considered in relation to organisational efficiency and patient-focused care.

It is apparent that care is generalised to meet the needs of the healthcare organisation and professionals and is less responsive to the needs of the older adult. Organisationally, if care delivery is generalised strategic planning for potential incidence increases can be managed. This approach supports the need for economies of time, effort, finance and efficiency. Thus, the functional approach to hip fracture may provide safer physical recovery, standardised care delivery, reduced complications and a shorter length of hospital stay.

This pragmatic view explains how organisations and professionals manage in an environment in which the number of admissions often outstrips the available beds. In an attempt to minimise 'bed blocking' many older adults with hip fracture are 'fast tracked' through the acute episode. Surgery takes place, post-operative complications managed and the team co-ordinates care to mobilise the patient for discharge. The emphasis in the healthcare facility's interest is to have patients assessed, treated and discharged in a timely manner (Chang et al., 2004; Koval and Cooley, 2005; Olsson et al., 2006; Watters and Moran, 2006). Restoration of function in a fiscally tight environment potentially drives practice.

Therefore targeting interventions, programmes or resources for functional return or decline is important. Predictors of recovery are useful to recognise and manage complications that may delay recovery. Recognising predictors such as age, preexisting conditions, complications post-surgery or prefracture activity along with 
specific tests such as "Timed Up \& Go" (Ingemarsson et al., 2003) or the Rehabilitation Activity Profile (van Balen et al., 2003) are strong indictors of functional return especially with walking or activity. Developing patient reported outcome measures (PROMs) to sit alongside current validated tools such as the SF-36 and condition specific evaluators will provide another perspective to the data collection methods already in practice. Predicator and measurement research are important to support best practice initiatives, reduce potential complications, decrease length of hospital stay and improve recovery outcomes overall.

Co-ordinated care is also important for hip fracture recovery. It was evident from the literature that co-ordinated care was medically led according to conditiontreatment decisions made. The primary focus was on the fix-repair initiative with the other health care team members following up care delivery once surgery was completed (Lichtblau, 2002). Siilarly medical lead care was the driver for improved outcomes when medical specialities provided co-care. For example, orthopaedic and geriatric specialties enhance care through medical 'collaborative' practice thereby improving injury related outcomes (Fisher et al., 2006). This condition-focused approach was very different to patient-centred care. However, moving older adults from acute care to specialised rehabilitation units is more common. This shifts care from a condition focus to meeting individual needs. However, the medical model of care dominates recovery processes and is seen in clinical pathways (Choong et al., 2000; Olsson et al., 2006; Roberts et al., 2004). Advocates of clinical pathways argue that this process benefits both patient and organisation by reducing in-hospital days and improving outcomes. Co-ordination of the multidisciplinary team through planning programmes or pathways focuses the professional to provide 'expert' care at designated times according to a preset approach to meet goals or criteria. Co-ordinated care improves efficiency of process. While acute care co-ordination is critical there is a need for comprehensive, co-ordinated and ongoing care that goes beyond the hospital period to ensure recovery is optimised (Morris and Zuckerman, 2002). Therefore, a professional understanding of recovery from hip fracture needs to be tempered with the post-discharge understanding of psychosocial recovery that is also important from the older adult's perspective.

In summary, an implicit taxonomy, a three staged approach to recovery is presented (Table1). In the recovery taxonomy, phase one includes the acute or in-hospital phase. 
The emphasis is on physical recovery from injury and surgery. The older adult is mobile with walking aids, relatively independent to self-care albeit with assistance, and assessed as 'safe to discharge' from acute care. Phase two is the rehabilitation stage. This may occur at an institution or in a normal residence. Age is often relevant to this stage. The older the adult the more likely they will need specialty rehabilitation for functional strengthening. If the person is younger rehabilitation tends to be homebased with outpatient or social/community input. The third phase is the enduring stage. There, older adults use their own previous health belief strategies to determine if and when they have recovered. Timeframes have not been added, as each phase varies according to external or internal factors impacting on the individual.

\section{Table 1: Hip fracture recovery taxonomy}

\begin{tabular}{|l|l|l|l|}
\hline Phase & Physical location & Properties & Phase goal \\
\hline Acute & $\begin{array}{l}\text { In hospital } \\
\text { episode }\end{array}$ & $\begin{array}{l}\text { Stable pre and post- } \\
\text { operatively } \\
\text { Minimal complications } \\
\text { Ambulated with } \\
\text { mobility aids } \\
\text { Self-care - grooming, } \\
\text { meals, toileting } \\
\text { Support network } \\
\text { available }\end{array}$ & $\begin{array}{l}\text { Survive injury and } \\
\text { surgery and achieve a } \\
\text { safe discharge from } \\
\text { acute care }\end{array}$ \\
\hline Rehabilitation & $\begin{array}{l}\text { Rehabilitation } \\
\text { facility or older } \\
\text { adult's residence }\end{array}$ & $\begin{array}{l}\text { Functional } \\
\text { strengthening } \\
\text { Managing co-existing } \\
\text { conditions } \\
\text { Adapting to } \\
\text { environments }\end{array}$ & $\begin{array}{l}\text { Return to prefracture } \\
\text { status or to an adapted } \\
\text { version }\end{array}$ \\
\hline Enduring & Normal residence & $\begin{array}{l}\text { Re-negotiating social } \\
\text { networks, physical } \\
\text { boundaries, } \\
\text { environments and } \\
\text { activities }\end{array}$ & To function as normal \\
\hline
\end{tabular}

It is also essential that a patient focused approach to recovery be included in future research. Emphasising understanding and improving potential outcomes for the older adult were evident in most studies but less obvious was the patient perspective. Exploring the psychosocial aspects of older adults in the recovery journey was more noticeable even though it was usually linked to function. However, research about the 
meaning and experience of recovery was limited. Understanding the older adult's view of hip fracture recovery could help healthcare professionals with future planning and delivery of care (Archibald, 2003; Borkan and Quirk, 1992; Robinson, 1999; Ziden et al., 2008). The patient perspective is important to balance the functional approach with the phased recovery taxonomy (Table 1). In phase one, it could be assumed an older adult will 'adhere' to healthcare 'instructions' to 'get through' the hospital episode and return home but have minimal control during this. The personal goal to return home balances the need to physically recover with participation in discharge planning. To be discharged the older adult achieves criteria that determine physical recovery. However, how the individual internalises meeting those physical recovery objectives depends on many factors. Once physical function is returned if somewhat limited, the older adult, through phases two and three draws on previous experiences and knowledge to manage the nonphysical aspects associated with the fracture and recovery. Robinson's (1999) work on transition suggests older adults use previous behaviours that support their recovery while meeting health professional's expectations as did other studies (Archibald, 2003; Ziden et al., 2008). Archibald (2003), Borkan and Quirk (1992), Robinson (1999), and Ziden et al. (2008) examining the patient perspective all suggest that being cognizant of the older adult's role in recovery will not only improve the prospects of the individual, but will also develop care regimes that reflect those outcomes.

A pragmatic requirement for shorter hospital stays, minimal healthcare risk activities and more standardised approaches to care delivery, influences current models of care. The management of episodes of care to ensure functional restoration is emphasised. This means that older adults must mobilise safely with walking aids, be able to selfcare and perform activities of daily living prior to discharge. This approach is problematic, as although functional recovery is assumed on discharge, psychosocial recovery may not have taken place or be in process. The initial in-hospital episode of recovery therefore provides a limited view of recovery, as it does not take into account patient transitions through acute, rehabilitation, and enduring recovery phases.

Somehow the healthcare sector needs to balance effective patient-centred care with the efficiency required in today's health environment. 


\section{Conclusion}

Organisational restructuring has emphasised clinical efficiency and the need to identify facts that promote a rapid recovery. This has produced a focus on restorative function. This was evident as $87 \%$ of the hip fracture literature reviewed was quantitative and medically lead. Something though has been lost. While quality of life and ageing issues are better understood, health professionals need to understand the patient-centric perspective as well. Recovery is complex and must be balanced with broader pragmatic, economic, and patient-centred issues that impact recovery. The growing emphasis on patient reported outcomes sitting alongside standardised evaluation tools will enhance patient centred understanding and reflect improved clinical practice. The mental health recovery models were not evident in hip fracture studies but these models could provide a framework for examining recovery that goes beyond the current physical restorative model of care. The suggested taxonomy of recovery may also benefit the clinical arena once it is examined and validated.

While clinician knowledge is gained through experience, studies on hip fracture recovery need to continue and ensure the patient's experience is included. It is critical therefore to develop nursing research in this area and develop nursing knowledge about recovery. This knowledge has the potential to improve recovery outcomes for the older adult, update clinicians' knowledge, and meets the intent of the Bone and Joint Decade, to improve the continuum of care for people with hip fracture through ongoing research. 


\section{References}

ACC, 2005. Preventing Injury from Falls: The National Strategy 2005-2015. Accident Compensation Corporation, New Zealand.

Archibald, G., 2003. Patients' experiences of hip fracture (Issues and innovation in nursing practice). Journal of Advanced Nursing 44 (4), 385-392.

Barangan, J.D., 1990. Factors that influence recovery from hip fracture during hospitalization. Orthopaedic Nursing 9 (5), 19-28.

Barnason, S., Zimmerman, L., Nieveen, J., Schulz, P., Miller, C., Hertzog, M., Rasmussen, D., 2008. Relationship between fatigue and early postoperative recovery outcomes over time in elderly patients undergoing coronary artery bypass graft surgery. Heart \& Lung 37 (4), 245-256.

Boonen, S., Autier, P., Barette, M., Vanderschueren, D., Lips, P., Haentjens, P., 2004. Functional outcome and quality of life following hip fracture in elderly women: a prospective controlled study. Osteoporosis International 15, 87-94.

Borkan, J.M., Quirk, M., 1992. Expectations and outcomes after hip fracture among the elderly. International Journal of Aging and Human Development 34 (4), 339-350.

Borkan, J.M., Quirk, M., Sullivan, M., 1991. Finding meaning after the fall: injury narratives from elderly hip fracture patients. Social Science \& Medicine 33 (8), 947957.

Chang, K.P., Center, J.R., Nguyen, T.V., Eismen, J.A., 2004. Incidence of hip and other osteoporotic fractures in elderly men and women: Dubbo Osteoporosis Epidemiology Study. Journal of Bone \& Mineral Research 19 (4), 532-536.

Choong, P.F.M., Langford, A.K., Dowsey, M.M., Santamaria, N.M., 2000. Clinical pathway for fractured neck of femur: a prospective, controlled study. The Medical Journal of Australia 172, 423-426.

Cree, M.W., 2004. Hip fracture-related changes in health ratings of older patients with cognitive impairment. Aging \& Mental Health 8 (6), 524-529.

Cummings, S.R., Phillips, S.L., Wheat, M.E., Black, D., Goosby, E., Wlodarczyk, D., Trafton, P., Jergesen, H., Winograd, C.H., Hulley, S.B., 1988. Recovery of function after hip fracture. The role of social supports. Journal of American Geriatric Society $36(9), 801-806$. 
Dawson, J., Doll, H., Fitzpatrick, R., Jenkinson, C., Carr, A., 2010. Routine use of patient reported outcome measures in healthcare settings. British Medical Journal 340 (186), 464- 467.

Dorsett, D., 1991. The trajectory of cancer recovery. Scholarly Inquiry for Nursing Practice 5 (3), 175-184.

Dowswell, G., Lawler, J., Dowswell, T., Young, J., Forster, A.,

Hearn, J., 2000. Investigating recovery from stroke: a qualitative study. Journal of Clinical Nursing 9, 507-515.

Eastwood, E.A., Magaziner, J., Wang, J., Silberzwieg, S.B., Hannan, E.L., Strauss, E., Siu, A.L., 2002. Patients with hipfractures: subgroups and their outcomes. Journal of American Geriatric Society 50, 1240-1249.

Egol, K.A., Koval, K.J., Zuckerman, J.D., 1997. Functional recovery following hip fracture in the elderly. Journal of Orthopaedic Trauma 11 (8), 594-599.

Ely, E.W., Wheeler, A.P., Thompson, B.T., Ancukiewicz, M., Steinberg, K.P., Bernard, G.R., 2002. Recovery rate and prognosis in older persons who develop acute lung injury and the acute respiratory distress syndrome. Annuals of Internal Medicine 136 (1), 25-36.

Fisher, A., Davis, M., Rubenach, S., Sivakumaran, S., Smith, P., Budge, M., 2006. Outcomes for older patients with hip fractures: the impact of orthopaedic and geriatric cocare. Journal of Orthopaedic Trauma 20 (3), 172-180.

Ganz, S.B., Peterson, M.G.E., Russo, P.W., Guccione, A.A., 2007. Functional recovery after hip fracture in the subacute setting. Hospital for Special Surgery Journal $3,50-57$.

Garratt, A., Schmidt, L., Mackintosh, A., Fitzpatrick, R., 2002. Quality of life measurement: bibliographic study of patientassessed health outcome measures. British Medical Journal 324 (7351), 1417-1422.

Giaquinto, S., Majolo, I., Roncacci, S., Sciarra, A., Vittoria, E., 2000. Very old people can have favorable outcome after hip fracture: 58 patients referred to rehabilitation. Archives of Gerontology and Geriatrics 31, 13-18. 
Givens, J.L., Sanft, T.B., Marcantonio, E.R., 2008. Functional recovery after hip fracture: the combined effects of depressive symptoms, cognitive impairment, and delirium. Journal of American Geriatric Society 56, 1075-1079.

Godfrey, M., Townsend, J., 2008. Older people in transition from illness to health: trajectories of recovery. Qualitative Health Research 18 (7), 939-951.

Greenhalgh, J., Long, A.F., Flynn, R., 2005. The use of patient reported outcome measures in routine clinical practice: lack of impact or lack of theory? Social Science \& Medicine 60 833-843.

Guccione, A.A., Fagerson, T.L., Anderson, J.J., 1996. Regaining functional independence in the acute care setting following hip fracture. Physical Therapy 76 (8), 818-826.

Gullberg, B., Johnell, O., Kanis, J.A., 1997. World-wide projections for hip fracture. Osteoporosis International 7, 407-413.

Halcomb, E., Davidson, P., 2005. Using the trajectory framework to describe recovery from traumatic injury. Contemporary Nurse 19 (1-2), 232-241.

Hall, S.E., Goldswain, P.R.T., Williams, J.A., Criddle, R.A., Senior, J.A., 2000. Hip fracture outcomes: quality of life and functional status in older adults living in the community. Australian New Zealand Journal of Medicine 30, 327-332.

Hallberg, I., Rosenqvist, A.M., Kartous, L., Lofman, O., Wahlstom, O., Toss, G., 2004. Health-related quality of life after osteoporotic fractures. Osteoporosis International $15,834-841$.

Hawkes, W.G., Wehren, L., Orwig, D., Hebel, J.R., Magaziner, J., 2006. Gender differences in functioning after hip fracture. Journal of Gerontology 61 (5), 495-499. Horan, M., Clague, J., 1999. Injury in the aging: recovery and rehabilitation. British Medical Bulletin 55 (4), 895-909.

Hunt, M.G., Stein, C.H., 2004. Living life to the fullest: well elders' views of hip fracture. Ageing International 29 (2), 178-198.

Ingemarsson, A.H., Frandin, K., Mellstrom, D., Moller, M., 2003. Walking ability and activity level after hip fracture in the elderly - a follow-up. Journal of Rehabilitation Medicine 35 (2), 76-83. 
Ishizaki, T., Imanaka, Y., Oh, E., Kuwabara, K., Hirose, M., Hayashida, K., Harada, Y., 2004. Association of hospital resource use with comorbidity status and patient age group among hip fracture patients in Japan. Health Policy 69, 179- 187.

Jacobson, N., Greenley, D., 2001. What is recovery? A conceptual model and explication. Psychiatric Services 52 (4), 482-485.

Jagmin, M.G., 1998. Postoperative mental status in elderly hip surgery patients. Orthopaedic Nursing 17 (6), 32-42.

Jette, A.M., Harris, B.A., Cleary, P.D., Campion, E.W., 1987. Functional recovery after hip fracture. Archives of Physical Medicine \& Rehabilitation 68 (10), 735-740. Johnell, O., Kanis, J.A., 2004. An estimate of worldwide prevalence, mortality and disability associated with hip fracture. Osteoporosis International 15, 897-902.

Kannus, P., Parkkari, J., Sievanen, H., Heinonen, A., Vuori, I., Jarvinen, M., 1996. Epidemiology of hip fractures. Bone 18 (Suppl. 1), 57S-63S.

Kearney, M.H., 1999. Understanding Women's Recovery from Illness and Trauma. Sage Publications, Thousand Oaks, CA, pp. 13-37.

Khasraghi, F.A., Lee, E.J., Christmas, C., Wenz, J.F., 2003. The economic impact of medical complications in geriatric patients with hip fracture. Orthopaedics 26 (1), 49 54.

Kirk-Sanchez, N., 2004. Factors related to activity limitations in a group of Cuban Americans before and after hip fracture. Physical Therapy 84 (5), 408-418.

Koot, V.C.M., Peeters, P.H.M., de Jong, J.R., Clevers, G.J., van der Werken, C., 2000. Functional results after treatment of hip fractures: a multicentre, prospective study in 215 patients. European Journal of Surgery 166, 480-485.

Koval, K., Cooley, M., 2005. Clinical pathway after hip fracture. Disability \& Rehabilitation 27 (18-19), 1053-1060.

Koval, K., Chen, A., Aharonoff, G., Egol, K., Zuckerman, J., 2004. Clinical pathway for hip fractures in the elderly: the Hospital for Joint Diseases experience. Clinical Orthopaedics and Related Research 425, 72-81. 
Koval, K.J., Skovron, M.L., Polatsch, D., Aharonoff, G.B., Zuckerman, J.D., 1996. Dependency after hip fracture in geriatric patients: a study of predictive factors. Journal of Orthopaedic Trauma 10 (8), 531-535.

Koval, K.J., Zuckerman, J.D., 1994. Functional recovery after fracture of the hip. The Journal of Bone and Joint Surgery (American) 76-A (5), 751-758.

Lappe, J.M., 1998. Prevention of hip fractures: a nursing imperative. Orthopaedic Nursing 17 (3), 15-24.

Lichtblau, S., 2002. Treatment of hip fractures in the elderly - the decision process The Mount Sinai Journal of Medicine 69 (4), 250-260.

Lin, P.C., Chang, S.Y., 2004. Functional recovery among elderly people one year after hip fracture surgery. Journal of Nursing Research 12 (1), 72-82.

Lofman, O., Berglund, K., Larsson, L., Toss, G., 2002. Changes in hip fracture epidemiology: redistribution between ages, genders and fracture types. Osteoporosis International 13 (1), 18-25.

Magaziner, J., Fredman, L., Hawkes, W., Hebel, J.R., Zimmerman, S., Orwig, D., Wehren, L., 2003. Changes in functional status attributable to hip fracture: a comparison of hip fracture patients to community-dwelling aged. American Journal of Epidemiology 157 (11), 1023-1031.

Magaziner, J., Hawkes, W., Hebel, J.R., Zimmerman, S.I., Fox, K.M., Dolan, M., Felsenthal, G., Kenzora, J., 2000. Recovery from hip fracture in eight areas of function. The Gerontological Society of America 55 (9), M498-M507.

Magaziner, J., Simonsick, E.M., Kashner, T.M., Hebel, J.R., Kenzora, J.E., 1990. Predictors of functional recovery one year following hospital discharge for hip fracture: a prospective study. Journal of Gerontology 45 (3), M101-M107.

Maher, A., Salmond, S.W., Pellino, T., 2002. Orthopaedic Nursing, third ed. W.B. Saunders, Philadelphia, pp. 1-26.

Melton III, L.J., 1996. Epidemiology of hip fractures: implications of the exponential increase with age. Bone 18 (Suppl. 3), 121S-125S.

Ministry of Health, 2003. Fracture of Neck of Femur Services in New Zealand Hospitals 1999/2000. Ministry of Health, Wellington, NZ. Retrieved from <http://www.moh.govt.nz>. 
Ministry of Health, 2007. Older People's Health Chart Book 2006. Ministry of Health, Wellington, NZ. Retrieved from <http:// www.moh.govt.nz >.

Morris, A., Zuckerman, J.D., 2002. National consensus conference on improving the continuum of care for patients with hip fracture. The Journal of Bone and Joint Surgery (American) 84, 670-674.

Mossey, J.M., Mutran, E., Knott, K., Craik, R., 1989. Determinants of recovery 12 months after hip fracture: the importance of psychosocial factors. American Journal of Public Health 79 (3), 279-286.

Mouzopoulos, G., Stamatakos, M., Arabatzi, H., Vasiliadis, G., Batanis, G., Tsembeli, A., Tzurbakis, M., Safioleas, M., 2008. The four-year functional result after displaced subcapital hip fracture treated with three different surgical options. International Orthopaedics 32, 367-373.

NZGG, 2003. Acute Management and Immediate Rehabilitation after Hip Fracture amongst People Aged 65 Years and Over. New Zealand Guidelines Group, Wellington, New Zealand.

Norton, R., Butler, M., Currie, R., Lee-Joe, T., Campbell, A.J., Reid, I.R., Gray, H., 1995. Hip fracture incidence among older people in Auckland: a population-based study. The New Zealand Medical Journal 108 (1010), 426-428.

Oldmeadow, L.B., Edwards, E.R., Kimmel, L.A., Kipen, E., Robertson, V.J., Bailey, M.J., 2006. No rest for the wounded: early ambulation after hip surgery accelerates recovery. ANZ Journal of Surgery 76, 607-611.

Olsson, L., Karlsson, J., Ekman, I., 2006. The integrated care pathway reduced the number of hospital days by half: a prospective comparative study of patients with acute hip fracture. Journal of Orthopaedic Surgery and Research 1 (3) (online publishing).

Ostendorf, M., van Stel, H.F., Buskens, E., Schrijvers, A.J.P., Marting, L.N., Verbout, A.J., Dhert, W.J.A., 2004. Patient reported outcome in total hip replacement. Journal of Bone and Joint Surgery 86 (6), 801-808.

Pande, I., Scott, D.L., O’Neill, T.W., Pritchard, C., Woolf, A.D., Davis, M.J., 2006. Quality of life, morbidity, and mortality after low trauma hip fracture in men. Annuals of the Rheumatic Diseases 65, 87-92. 
Peterson, M.G.E., Allegrante, J.P., Cornell, C.N., MacKenzie, C.R., Robbins, L., Horton, R., Ganz, S.B., Augurt, A., 2002. Measuring recovery after hip fracture using the SF-36 and Cummings scales. Osteoporosis International 13, 296-302.

Randell, A.G., Nguyen, T.V., Bhalerao, N., Silverman, S.L., Sambrook, P.N., Eisman, J.A., 2000. Deterioration in quality of life following hip fracture: a prospective study. Osteoporosis International 11, 460-466.

Repper, J., Perkins, R., 2003. Social Inclusion and Recovery: A Model for Mental Health Practice. Bailliere Tindall, London.

Richmond, T., Thompson, H., Deatrick, J., Kauder, D., 2000. Journey towards recovery following physical trauma. Journal of Advanced Nursing 32 (6), 1341-1347.

Roberts, C., Pickering, R., Onslow, E., Clancy, M., Powell, J., Roberts, A., Hughes, K., Coulson, D., Bray, J., 2004. The effectiveness of implementing a care pathway for femoral neck fracture in older adult people: a prospective controlled before and after study. Age and Ageing 33, 178-184.

Roberts, G., Wolfson, P., 2006. New directions in rehabilitation: learning from the recovery movement. In: Roberts, G.,Davenport, S., Holloway, F., Tatton, T. (Eds.), EnablingRecovery: The Principles and Practice of Rehabilitation Psychiatry. Gaskell, London.

Robinson, S.B., 1999. Transitions in the lives of elderly women who have sustained hip fractures (Issues and Innovations in nursing practice). Journal of Advanced Nursing 30 (6), 1341-1348.

Sanders, K.M., Nicholson, G.C., Ugoni, A.M., Pasco, J.A., Seeman, E., Kotowisz, M.A., 1999a. Health burden of hip and other fractures in Australia beyond 2000: projections based on the Geelong osteoporosis study. The Medical Journal of Australia 170 (10), 467-470.

Sanders, K.M., Seeman, E., Ugoni, A.M., Pasco, J.A., Martin, T.J., Skoric, B., Nicolson, G.C., Kotowicz, M.A., 1999b. Age- and gender-specific rate of fractures in Australia: a population based study. Osteoporosis International 10 (3), 240-247.

Shah, M.R., Aharonoff, G.B., Wolinsky, F.D., Zuckerman, J.D., Koval, K.J., 2001. Outcome after hip fracture in individuals ninety years of age and older. Journal of Orthopaedic Trauma 15 (1), 34-39. 
Shyu, Y., Chen, M., Liang, J., Lu, J., Wu, C., Su, J., 2004. Changes in quality of life among elderly patients with hip fracture in Taiwan. Osteoporosis International 15, 95102.

Siu, A.L., Boockvar, K.S., Penrod, J.D., Morrison, R.S., Halm, E.A., Litke, A., Silberzweig, S., Teresi, J., Ocepek-Welikson, K., Magaziner, J., 2006. Effect of inpatient quality of care on functional outcomes in patients with hip fracture. Medical Care 44 (9), 862-869.

Stephenson, S., Langley, J., Campbell, J., Gillespie, W., 2003. Upward trends in the incidence of neck of femur fractures in the elderly. The New Zealand Medical Journal $116(1185), 665$.

Tanaka, J., Tokimura, F., Seki, N., 2003. Outcomes of hip fracture surgery in patients aged $>90$ years. Orthopaedics $26(1), 55-58$.

Titler, M., Dochterman, J., Xie, X.-J., Kanak, M., Fei, Q., Picone, D.M., Shever, L., 2006. Nursing interventions and other factors associated with discharge disposition in older patients with hip fractures. Nursing Research 55 (4), 231- 242.

Tsauo, J., Leu, W., Chen, Y., Yang, R., 2005. Effects on function and quality of life of postoperative home-based physical therapy for patients with hip fracture. Archives of Physical Medicine \& Rehabilitation 86, 1953-1957.

Van Balen, R., Essink-Bot, M.L., Steyerberg, E.W., Cools, H.J.M., Habbema, J.D.F., 2003. Quality of life after hip fracture: a comparison of four health status measures in 208 patients. Disability \& Rehabilitation 25 (10), 507-519.

Van Balen, R., Steyerberg, E.W., Polder, J.J., Ribbers, T.L., Habbema, J.D.F., Cools, H.J.M., 2001. Hip fracture in elderly patients: outcomes for function, quality of life, and type of residence. Clinical Orthopaedics and Related Research 390, 232-243. Watters, C., Moran, W., 2006. Hip fractures- a joint effort. Orthopaedic Nursing 25 (3), 157-165.

Williams, A., Dunning, T., Manias, E., 2007. Continuity of care and general wellbeing of patients with comorbidities requiring joint replacement. Journal of Advanced Nursing 57 (3), 244-256. 
Young, Y., Brant, L., German, P., Kenzora, J.E., Magaziner, J., 1997. A longitudinal examination of functional recovery among older people with subcapital hip fractures. Journal of American Geriatric Society 45 (3), 288-294.

Zalon, M.L., 2004. Correlates of recovery among older adults after major abdominal surgery. Nursing Research 53 (2), 99- 106.

Ziden, L., Wenestam, C.-G., Hannsson-Scherman, M., 2008. A life-breaking event: early experiences of the consequences of a hip fracture for elderly people. Clinical Rehabilitation 22, 801-811.

Zuckerman, J.D., Koval, K.J., Aharonoff, G.B., Hiebert, R., Skovron, M.L., 2000a. A functional recovery score for elderly hip fracture patients: 1 . Development. Journal of Orthopaedic Trauma 14 (1), 20-25.

Zuckerman, J.D., Koval, K.J., Aharonoff, G.B., Skovron, M.L., 2000b. A functional recovery score for elderly hip fracture patients: 11 . Validity and Reliability. Journal of Orthopaedic Trauma 14 (1), 26-30. 